\title{
Exploring the use of a dynamic online software programme in the teaching and learning of trigonometric graphs
}

\begin{abstract}
Authors:
Jayaluxmi Naidoo ${ }^{1}$

Reginald Govender ${ }^{2}$

Affiliations:

${ }^{1}$ School of Education, College of Humanities, University of KwaZulu-Natal, South Africa

${ }^{2}$ Kingsway High School, KwaZulu-Natal, South Africa

Correspondence to:

Jayaluxmi Naidoo

Email:

naidooj2@ukzn.ac.za

Postal address:

11 Ronald Place, Westville

3629, South Africa

Dates:

Received: 06 Mar. 2014

Accepted: 17 Nov. 2014

Published: 12 Dec. 2014

How to cite this article:

Naidoo, J., \& Govender, R.

(2014). Exploring the use of

a dynamic online software

programme in the teaching

and learning of trigonometric graphs. Pythagoras, 35(2),

Art. \#260, 12 pages. http://

dx.doi.org/10.4102/

pythagoras.v35i2.260

\section{Copyright:}

C) 2014. The Authors.

Licensee: AOSIS

OpenJournals. This work is

licensed under the Creative

Commons Attribution

License.
\end{abstract}

\section{Read online:}

Scan this $Q R$ code with your smart phone or mobile device to read online.
Trigonometry is an important section in mathematics that links algebraic, geometric and graphical reasoning. Many secondary school learners are not familiar with these types of reasoning; thus, trigonometry presents a challenge for these learners. The traditional 'chalk and talk' method of teaching trigonometry is used by many teachers; however, this article is based on a case study that explores the innovative use of a dynamic online software program in the teaching and learning of Grade 10 trigonometric graphs. The participants in this study were 25 Grade 10 mathematics learners from one school in the south of Durban, KwaZulu-Natal, South Africa. Data were collected by using two trigonometry worksheets, semi-structured interviews with selected learners and lesson observations. The worksheets were constructed based on the following focus areas: behaviour of graphs, interpretation of graphs, modelling and overall performance of the learner. In all focus areas, the participants' scores improved significantly when working within the dynamic online environment. Further analysis revealed the following five themes: easy access, learners in control, technology is the future, motivation and meaningful interaction. These findings would be of interest to mathematics teachers, learners, curriculum developers and mathematics teacher educators.

\section{Introduction}

Technology is developing rapidly and captures the interest and attention of learners in contemporary society. Technology-based tools transform mathematics concepts to an understandable form for learners (Niess, 2006). Ndlovu, Wessels and De Villiers (2011) explain that there is an increasing trend to integrate technology into mathematics education in many countries globally. Technology-based tools for mathematics may include software (programs) and hardware (devices). This study focuses on the innovative use of the dynamic online software ${ }^{1}$ Geogebra $^{2}$ when teaching Grade 10 trigonometric graphs. The study explores the implications of the use of this dynamic online software program when teaching trigonometric graphs in mathematics.

Research (Anthony \& Walshaw, 2009; Leendertz, Blignaut, Nieuwoudt, Els \& Ellis, 2013; Lin, 2008) has indicated that the use of technology enhances the teaching and learning of mathematics. The use of technology-based tools enriches learning, since visual data promotes and challenges explanation and justification, as opposed to the traditional methods of note taking, chalk and talk. This may add value when teaching trigonometric graphs since many learners perform poorly and struggle with trigonometric graphs (Weber, 2008). Additionally, many mathematics teachers face challenges when trying to effectively introduce the concept of trigonometric graphs to learners (Klein \& Hamilton, 1997).

The nature of the Geogebra program is that it allows the mathematics learner the freedom to manipulate and visually notice instantaneous changes and behaviour of graphs. The Geogebra program was used to create the tasks offline. Once the offline dynamic file was created, it was then converted to an applet and uploaded to the Internet, thus creating a dynamic online environment (Govender, 2013). Hence, this research study sought to answer the following question: What are the implications of using dynamic online software when teaching trigonometric graphs in Grade 10 mathematics? 1.Dynamic online software is used for teaching mathematics in a discovery mode. Learners are encouraged to use computer software
(such as Geometer's Sketchpad or Geogebra) to construct figures that can be altered by dragging points around the computer screen whilst the underlying relationships are unchanged.

2.A dynamic online program that may be used for teaching mathematics. 


\section{Technology-based tools for the teaching and learning of mathematics}

There is a range of available technology-based tools that could be used within mathematics classrooms including scientific calculators, function graphers, spreadsheets, statistical packages, subject-specific websites, interactive whiteboards and geometry packages (Niess, 2006; Pierce \& Ball, 2009). Technology-based devices, for example clickers and voting pods, may be used in collaboration with statistical packages to determine how many learners agree on a particular solution whilst working within a mathematics lesson. Scientific calculators and function graphers are regularly used by learners and teachers in mathematics classrooms. In some cases these technology-based tools are allowed to be used in tests and examinations. Using these tools saves time and eliminates redundant and complex calculations in mathematics.

Spreadsheets and statistical packages are currently used in mathematics classrooms to process raw data into meaningful information. These technology-based tools may also be used when teaching and learning specific concepts in mathematics, for example mean, mode, range, median, population, data representation and problem solving. Similarly, interactive whiteboards assist the teacher, as they allow for the recording of mathematics lessons for later use or sharing of mathematics lessons in real time. These hi-tech whiteboards offer an unlimited supply of digital colour that will never run out and a list of programs to enhance the mathematics teaching process. Thus, the use of technology-based tools in the teaching of mathematics ought to make a difference in a classroom. However, this also necessitates that mathematics teachers possess and exhibit sound technological pedagogical content knowledge (Koh \& Sing, 2011). This term epitomises how a teacher integrates technology-based tools effectively within the classroom (Mishra \& Koehler, 2006).

\section{Dynamic technology}

Dynamic technology offers the learner the freedom to manipulate shapes and graphs as compared to the more static nature of sketches. Mathematics is seen as a conceptual subject in which face-to-face contact is necessary for conveying concepts such as trigonometry (Engelbrecht \& Harding, 2005). Hence, the use of technology-based tools depends on the teacher's attitude towards these tools, since the teacher is the most important factor within the classroom. Many teachers believe that technology-based tools will not enhance learning and subsequently these teachers resist their use in the classroom (Niess, 2006). However, Pierce and Ball (2009) maintain that teachers' opinions are bound to change as they are exposed to positive results through the use of technology-based tools within the classroom milieu.

Learners are required to generate as many graphs as necessary first by pen and paper and then to support these drawings by available technology-based tools (Department of Basic Education, 2011). It is likely that learners will understand features pertaining to trigonometric graphs more quickly, through the use of dynamic online software, as compared to the traditional methods of pen, paper, chalk and talk. The integration of dynamic online software in meaningful ways may enhance the construction of knowledge in addition to the communication and dissemination of ideas in the mathematics classroom. Visualisation and stimulation are the primary advantages of using dynamic online software and may be the initial step in achieving interactive learning environments that support the teaching and learning of abstract mathematics concepts (Naidoo, 2012). According to Robert and Slavin (2009), this learning environment replaces the teacher with self-paced instructions. This promotes a learner-centred environment and allows learners to control their learning whether they are in the classroom or not. Hence it is important to note that the use of dynamic online software enables the learner to become self-regulated because these programs have the capability of placing accurate solutions and processes at learners' fingertips.

Thus the use of dynamic online software influences two major cornerstones in post-apartheid teaching and learning environments within South Africa: learner-centred education and self-regulation. These concepts share a commonality that the learner is able to think independently and only requires the teacher's assistance when they encounter problems. The teacher acts as the facilitator; therefore, learner centredness and self-regulation may be applied and practised through the use of dynamic online technology. Figure 1 illustrates the relationship between the use of dynamic online technology, learner centredness and self-regulation. As is evident this figure portrays a cyclic relationship between all three components.

Teaching trigonometric graphs with the aid of dynamic online software is more likely to result in an individualised learnercentred milieu within the classroom. Learners are allowed to make mistakes freely without embarrassment or being looked down upon by peers when working within a dynamic online environment. This dynamic environment provides the learner with a sense of control as they do not just do mathematics but experience the mathematics. Learners who experience difficulty in mathematics are likely to change their attitude to mathematics through the use of dynamic software in mathematics (Pierce \& Ball, 2009). The environment is

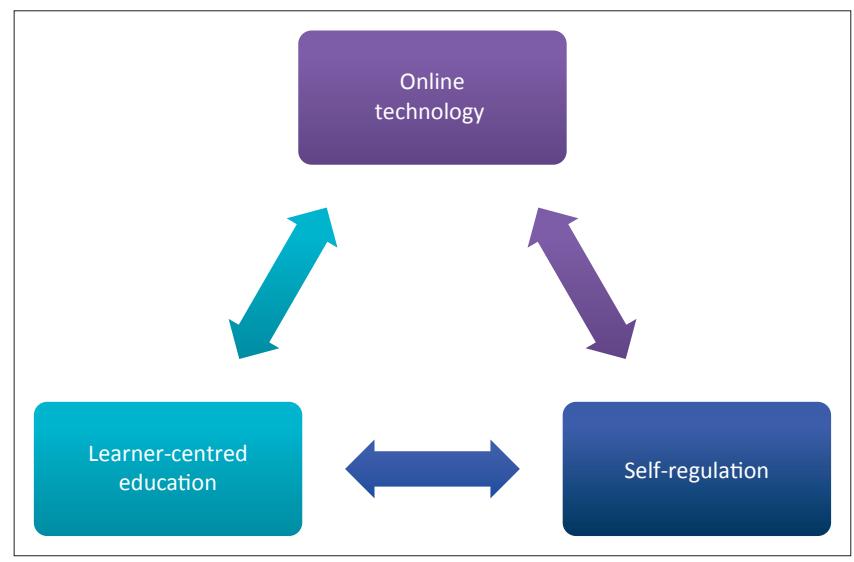

FIGURE 1: The effects of dynamic online technology on teaching and learning mathematics. 
online and thus it is available to anyone who has Internet access, permitting learning at any time and in any place such that distance does not become an obstacle to education (De Villiers, 2013). Furthermore, since this type of learning is not restricted to the classroom and school environment, there is a likelihood of increased and improved parental involvement.

\section{Theoretical framing: The ADDIE model}

This case study adopted the Analysis-Design-DevelopImplement-Evaluate (ADDIE) model of instructional design (Danks, 2011). The ADDIE model was initially created for use by the United States Armed forces in the early 1970s and entailed 19 stages or phases that were considered crucial to the advancement of educational and training programmes (Hannum, 2005). Now the ADDIE model represents guidelines for building effective training and performance tools in five phases. When applied to this study the teacher is the instructional designer who would examine the delivery of teaching trigonometric graphs to enhance learning. This study has been designed according to the following five phases that collectively constitute the ADDIE model:

- Analysis

- Design

- Development

- Implementation

- Evaluation.

The analysis stage is a process that determines what is going to be learned and for whom it is intended. The designer would need to identify the problem, goals, learner needs and existing knowledge (Danks, 2011). The latter part relates to Vygotsky's zone of proximal development (Vygotsky, 1978), which is crucial to the teaching and learning process. The zone of proximal development can be described in terms of mathematics, as the space between what the learner knows and the mathematics they are about to learn. Within the analysis stage other relevant considerations must be taken into account such as the learning environment, the boundaries, the delivery decisions and the timeline for the project (Hoffman, Ritchie \& Marshall, 2006). On completion of the analysis stage, the designing of the blueprint for the material to be implemented begins.
The design stage comprises of examining and specifying how materials are to be used or learned by learners (Morrison, Ross \& Kemp, 2004). The definition of the exact content of the material needs to be established together with the design of activities and assessment. Following the design stage is the development of the learning materials phase. This stage involves the creation of the course structure, content, activities and assessments. In relation to the study at this stage, the dynamic trigonometric graph content was uploaded to the Web and examined to see whether or not the material operated as expected. This served as the pilot for the uploaded content and assisted in achieving validity and reliability of the uploaded activity.

The implementation stage is a process of delivering the piloted and adjusted material to the learners. The delivery of the material (final product) can take on various forms such as a web page (Morgan, 2011), which results in meaningful engagement with the dynamic online trigonometric graphs. It is important to note that although learners engage with the content on their own, the teacher takes on an active role. The teacher, as the developer, would need to continuously analyse, redesign and enhance the product in order for it to be delivered effectively. This would involve the teacher observing learners' engagement with the material to see whether or not they appear enthusiastic, resistant or critical in their use of the material.

Lastly the evaluation stage involves measuring the effectiveness and efficiency of the material. The evaluation stage is a two-stage process: the summative and formative stages. Formative evaluation encompasses the data that inform revision decisions. The summative approach evaluates the validity of the learning; validity is assessed at the completion of the project. The teacher as the designer is focused on achieving the requirements of the curriculum as stipulated by policy documents (Department of Basic Education, 2011). This is done to ensure that quality learning takes place. Thus, formative evaluation is ideal, since assessment can take place at each stage to refine and redevelop strategies for attaining predetermined goals. This allows for close inspection between progressions rather than at the end of the process. A schematic drawing of the ADDIE model that was applied in this case study is illustrated in Figure 2.

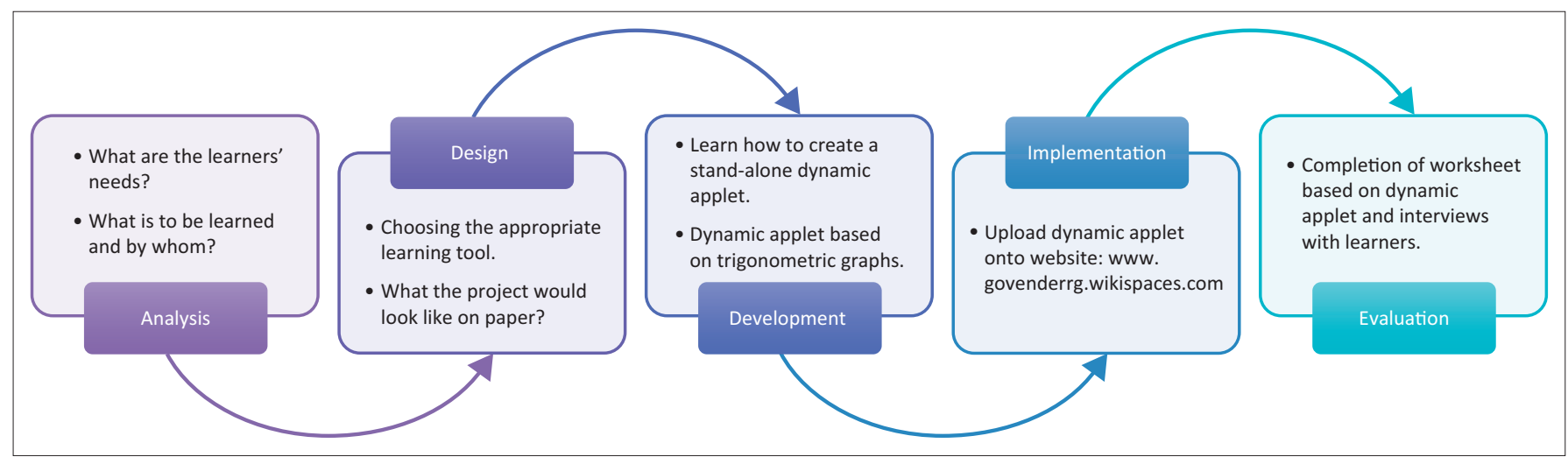

FIGURE 2: The ADDIE model as used in this case study. 
As is evident in Figure 2, it is essential that the use of technology-based tools do not hinder the teaching and learning of mathematics. The technology plan ought to focus on how technology-based tools may be implemented, to foster the teaching and learning process. The ADDIE model is described as a framework for instructional design that guides the teacher to attempt material development and design in a logical way (Bichelmeyer, 2005).

\section{Methodology Ethical considerations}

Ethical clearance was obtained from the participating university's research office and the Department of Basic Education. In addition, consent was obtained from the principal, participants, parents of all participants and the governing body of the school that the participants attended. Participants and parents were provided with a letter detailing the aim and methodology of the study; in addition, participants were informed of their right to withdraw from the study. All participants' responses on both worksheets were coded and participants were allocated pseudonyms to protect their identity. Participants and their parents provided permission for the video recording of interviews and observations.

\section{Data collection}

This case study set out to explore the implications of using a dynamic online software program in the teaching and learning of trigonometric graphs in Grade 10. Worksheets, interviews and observations were used to collect data for this study. Data collection through the use of various methods enhances the reliability and validity of the study (Bertram, 2010; Padayachee, Boshoff, Olivier \& Harding, 2011).

\section{Pilot phase: During the development stage}

The worksheets (Appendix 1 and Appendix 2) and semistructured interview schedule (Appendix 3) were piloted with a sample of five Grade 10 learners with mixed levels of mathematics ability. The learners' mathematics ability levels for the pilot and main study were established by analysing the learner's previous test and examination scores in mathematics. Piloting the research instruments assisted in assessing the validity and reliability of each instrument. There was a need to ensure that each instrument was suitable and adequate for collecting the data that was required. After minor adjustments were made to the research instruments, the main study commenced.

\section{During the evaluation stage}

Two worksheets were answered by 25 Grade 10 learners to evaluate their understanding of trigonometric graphs before and after the use of the dynamic online software. The worksheets were developed by using the Geogebra software and focused on the sine and cosine functions in trigonometry only. The selected questions assessed learners' development and understanding of trigonometric graphs. The worksheets contained four questions. Question 1 and Question 2 set out to assess learners' understanding of the behaviour of trigonometric graphs. Question 3 set out to examine the learners' ability to interpret the trigonometric functions whilst examining a graphical representation. Question 4 evaluated their ability to apply trigonometry to a real-life problem. Learners had to answer questions using pencil and paper first (Appendix 1) and then interact within the dynamic online environment to sketch graphs and complete solutions to questions in the second worksheet (Appendix 2). According to the Van Hiele theory, the exploration of functions ought to be completed before arriving at the formulae (De Villiers, 2013). This was observed as learners progressed from Question 1 to Question 4. The element of visualisation, which is aided by the software, plays an important role in the exploration of trigonometric graphs. It must be noted that the learners were not coached on how to answer the questions using the dynamic online environment. Learners were not given repeated chances to complete the worksheets: learners completed each worksheet only once.

Subsequently, one-on-one interviews were conducted with five randomly selected learners after the completion of the second worksheet. A semi-structured interview schedule, which consisted of 10 items, was used. The interview schedule consisted of both closed and open-ended questions (see Appendix 3). The use of open-ended questions resulted in rich qualitative data. This assisted in providing a deeper interpretation of learners' experiences. Data were also collected via observations of learners whilst they completed the worksheets. The observations were video recorded. Data collected via the observation allowed the researcher to gain additional insights into each learner's methods and processes as learners completed the worksheets.

\section{Findings and discussion The worksheets}

Twenty-five Grade 10 learners of mixed ability levels participated in this study. The maximum possible score that a learner could obtain was 20 on each worksheet. One mark per correct answer was allocated: the learner would have given either had the correct (awarded 1) or incorrect answer (awarded 0). The worksheets consisted of four questions that assessed specific aspects of trigonometric graphs.

Learners had to first answer questions using a pencil and paper and then complete the second worksheet whilst working within a dynamic online environment. It was evident based on the analysis of the worksheets that learners' scores improved when working within the dynamic online environment. An overall average of $91 \%$ was achieved in the online environment as compared to an overall average of $70.3 \%$ that was achieved by the same group of learners when they used pencil and paper to complete the first worksheet. It was evident that as learners interacted with the activity within a dynamic online environment, they grasped concepts 
and ideas more successfully. It would seem that learners could analyse and interpret the behaviour of graphs with more success as they manipulated the trigonometric graphs within the dynamic online environment. The performance of learners in the second worksheet is illustrated in Figure 3.

The second worksheet was analysed statistically to explore learner performance in each question. A tabulated description of learner performance when working within the dynamic online environment is exhibited in Table 1.

\section{Behaviour of graphs}

The mean for this section (Question 1 and Question 2) was 7.72. The mean indicated that learners displayed a good understanding of the behaviour of the graphs. Additionally, a median value of 8 was calculated. This was also the maximum mark for this section. The standard deviation of 0.46 indicates that the values were not widely dispersed from the mean of 7.72. The minimum value of 7.00 suggests that learners have a good understanding of the behaviour of trigonometric graphs with the aid of dynamic online technology. It is also worthy to note that learners performed better in this section as compared to the other sections. Based on this evidence it would seem that as learners manipulated the trigonometric graphs within the dynamic online environment their knowledge and skills related to answering questions based on the behaviour of trigonometric graphs were enhanced.

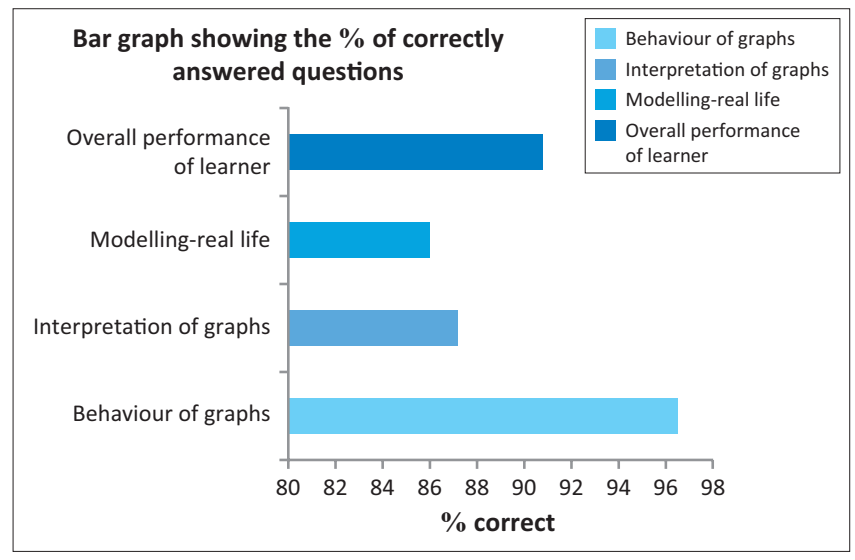

FIGURE 3: Graphical representation of the percentage of correctly answered questions in the second worksheet.

\section{Interpretation of graphs}

When analysing learner performance in Question 3 of the worksheet, it was found that the spread from the mean of 8.72 was 1.73 (standard deviation) with a maximum value of 10 and minimum value of 6 . The median is 9 with the median of the lower half (Q1) being 8 and the median of the upper half (Q2) being 10. This indicates that the majority of learners displayed a good understanding of the interpretation of trigonometric graphs. A minimum value of 6 and a difference of 1.28 between the mean and the total of this section indicate that learners could have done better. It is noted that this section had a pass percentage of $87 \%$ which is the second lowest when compared to the other sections. So, whilst learners could have scored higher marks in this question, it was evident that their skills and knowledge related to the interpretation of graphs were enhanced by their use of the dynamic online program.

\section{Modelling real-life contexts}

The maximum value for Question 4 was 2 with a minimum value of 0 . The standard deviation was 0.54 with a mean value of 1.72 . The coefficient variation was 0.31 which was the highest when compared to the other sections. It can be deduced that learners performed poorly in this section. This deduction is supported by the $86 \%$ pass in this question which was the lowest percentage achieved.

\section{Overall performance}

When answering all questions on the worksheet, the learners displayed an overall performance of $91 \%$ with a mean of 18.16 . There was a minimum outlier and minimum value of 15 . Despite these values, the majority of learners performed well on the worksheet whilst working within the dynamic online environment. This implies that the learners' performance improved as a result of working within the dynamic online environment. The difference of 1.84 between the mean and the total of this section indicates that there could be room for improvement as it was $9 \%$ short of $100 \%$. However, learners did score more than $85 \%$ in all sections. It would seem that the learner's skills, understanding and knowledge of answering questions related to trigonometric graphs was enhanced through the use of the dynamic online environment.

TABLE 1: Learner competence when working within a dynamic online environment.

\begin{tabular}{|c|c|c|c|c|}
\hline Parameter & $\begin{array}{c}\text { Behaviour of graphs } \\
\text { (Question } 1 \text { and Question 2) }\end{array}$ & $\begin{array}{l}\text { Interpretation of graphs } \\
\text { (Question 3) }\end{array}$ & $\begin{array}{l}\text { Modelling real life } \\
\text { (Question 4) }\end{array}$ & Overall performance of learner \\
\hline Total marks allocated & 8 & 10 & 2 & 20 \\
\hline Minimum & 7.00 & 6.00 & 0.00 & 15.00 \\
\hline Question 1 & 7.00 & 8.00 & 2.00 & 18.00 \\
\hline Question 2 (median) & 8.00 & 9.00 & 2.00 & 18.00 \\
\hline Question 3 & 8.00 & 10.00 & 2.00 & 19.00 \\
\hline Maximum & 8.00 & 10.00 & 2.00 & 20.00 \\
\hline Mean & 7.72 & 8.72 & 1.72 & 18.16 \\
\hline Interquartile range & 1.00 & 2.00 & 0.00 & 1.00 \\
\hline Semi-interquartile range & 0.50 & 1.00 & 0.00 & 0.50 \\
\hline Standard deviation & 0.46 & 1.37 & 0.54 & 1.49 \\
\hline Coefficient variance & 0.06 & 0.16 & 0.31 & 0.08 \\
\hline Total of all participants & 193 & 218 & 43 & 454 \\
\hline Total percentage & 97 & 87 & 86 & 91 \\
\hline
\end{tabular}




\section{The semi-structured interview and observations}

The analysis of the learner semi-structured interviews (LI) was done concurrently whilst analysing data collected during the observations. All interviews were transcribed and the key ideas that emerged from the transcripts were grouped together. All key ideas were then analysed qualitatively whilst the observations were reviewed to ensure that there were no misunderstandings or miscommunications. The key ideas were then categorised according to overarching common themes. Thus, the interview transcripts were analysed using thematic coding and categorisation. Data collected from the semi-structured interviews and observations gave rise to the following themes: easy access, learners in control, technology is the future, motivation and meaningful interaction.

\section{Easy access}

We live in a fast-paced technological world in which education is now at our fingertips. This is made easier with applications that run on our mobile devices such as Mystery Math Town, ABC Trains and Google Sky Maps. Similarly, many mundane daily activities may be done within seconds without leaving your home. This type of lifestyle is referred to as Cybersphere (Hoehler, 2013). The learning environment on the Internet is easily accessible for learners as it is not restricted to the school environment only. This is supported by the participants as is evident from the following excerpts:

Shivaan: I would go on the website, especially at home because there is Internet and computer access. (LI, 14 June 2013)

Bradley: Anywhere it's available preferably at home. (LI, 14 June 2013)

Teaching trigonometry through the use of dynamic online software is perceived as an easier mode to communicate with learners. When the teaching and learning environment is comfortable, it becomes conducive to learning. This is evident in the following excerpts:

Bradley: I feel more comfortable in learning how to go about the questions and processes to get the answer. (LI, 14 June 2013)

Tahlia: I have both aspects ... technical part and ... tactile part ... from the teacher. (LI, 14 June 2013)

It was noted that learners were more relaxed when working with the second worksheet whilst working in the dynamic online environment. Additionally, working with mathematics within a dynamic online environment is beneficial for parents who do not have time or are not mathematically inclined to help their children with their mathematics homework. It was noted during the completion of the second worksheet that learners were confident in using the use of the dynamic online software, as is evident from this excerpt:

Andile: It's nice ... it's really different. I feel a lot more comfortable because we are the generation that interacts a lot with technology so it's kind of normal and comfortable for us. (LI, 14 June 2013)

\section{Learners in control}

A sense of independence was noticed whilst learners completed the second worksheet. Learners were engaging in their own learning process and seldom with their peers. Very little assistance from the teacher was requested as opposed to when learners answered the first worksheet. Learners played an active role rather than a passive one in their learning of trigonometric graphs whilst working in the dynamic online environment. This is corroborated by Dylan's comment: 'It is more easy than having a teacher speak to you and teach you in a classroom' (LI, 14 June 2013).

Teachers are generally seen as gatekeepers of knowledge whereas using this kind of technology allows learners to control their own learning. Learners have the freedom to explore and discover independently. It was noted that as learners changed the amplitude and period (vertical and horizontal shifts) of the trigonometric graphs, they jotted down notes about the changes in the graph. It was evident that their knowledge and skills for answering questions based on trigonometric graphs were significantly enhanced by working within the dynamic online environment. Following along similar lines, Clements, Julie, Yelland and Glass (2008) maintain that concepts are more likely to be lodged in longterm memory when learners make notes. Thus, greater understanding takes place as learners become participators rather than spectators in the learning process. This notion is supported by the following excerpts:

Bradley: I find it very useful because I can be involved in the process of learning on how to do mathematics. (LI, 14 June 2013)

Tahlia: It is a nice way to reinforce what I had learnt and I can see those visual images. ... I can remember that in my mind rather the words and the written text. (LI, 14 June 2013)

The use of Web-based learning contributes to learner-centred education since the teacher takes on the role of the facilitator. The learning experience offered through the dynamic online environment is more than just accepting some sort of given mathematical fact from the teacher. This is supported by this excerpt:

Shivaan: In class if you want to know something you have to ask the teacher, they would have to draw a diagram to explain to you. ... This way you can do it yourself. It was much better for your understanding; you can change the amplitude. (LI, 14 June 2013)

Through the observations, it was noted that all the learners were fully engaged in each task with very little teacher interaction or participation during the learning process. Thus, self-regulation occurs when learners are given the opportunity to think about their own learning process and make meaning of this process by themselves. This is exemplified by this comment:

Bradley: The concepts being taught are much easier because I can get in and change ... you know like the equation of the trigonometric graph ... so I can see the different ways on how it changes and why it changes. (LI, 14 June 2013) 
Thus, it was evident from the data collected that the learners participating in the study were in full control as they experienced the changes in the shape and position of trigonometric graphs first hand. This first-hand experience assisted in self-assuring the participating learners of their reasoning. The learners' reasoning skills and knowledge related to changing the values in the equations of trigonometric graphs were significantly improved. Learners could now see and deduce the impact of these changes on the shape and position of the trigonometric graphs.

\section{Technology is the future}

The very essence of integrating technology and mathematics demonstrates a progressive development in mathematics education. It moves from the unmotivated norm of pen and paper to a discipline that utilises technology-based tools within the teaching and learning process. Following along similar lines Andile indicated that '[o]bviously our world is continuously moving ahead towards technology and eventually I believe that all lessons will be taught only with technology' (LI, 14 June 2013).

Adding to this, walking into a class with technology according to Shivaan is 'not a daunting thing. It's a very good thing to walk into a classroom with technology as it shows development in maths' (LI, 14 June 2013).

Similarly, Andile stated that the concepts in mathematics are more accessible at a level which we can understand. ... We interact a lot with technology and this is just putting something that we learn at school in our form of communication. (LI, 14 June 2013)

As is evident from the excerpts from the interview transcripts, the participating learners were able to comprehend concepts being taught more easily through the use of technologybased tools. The participants were enthusiastic about using technology-based tools and they indicated that they enjoyed using these tools. The participants' cognitive development was enhanced through the use of technology-based tools. They were of the belief that they were now exposed to new technology and how it works. This is validated by the following excerpts:

Tahlia: Now we are living in a time where technology is all over. So if you used to it already then it won't be so foreign when you come across it later. (LI, 14 June 2013)

Shivaan: So much technology around us and by doing this you get exposed to new types of technology. (LI, 14 June 2013)

As indicated earlier, there are many types of technologybased tools that may be used to support mathematical investigations and connections without any specialised training on how to use them. Technology-based tools are designed to make our lifestyle easier and their emergence in mathematics is definitely useful. This implies that teachers do not need to spend as much time sketching or re-sketching a function on the board or attempt to explain a 3D phenomenon in a $2 \mathrm{D}$ environment.

\section{Motivation}

It was noted through observations and the interviews that all learners described and demonstrated the completion of the activity in collaboration with the dynamic online software as an exciting and exhilarating experience. Attractiveness and entertainment value are the core properties of animations, which make them a motivating form of presentation with the ability to sustain one's attention (Lowe, 2001). Similarly, Bradley stated that: 'I am more open to this idea of learning about maths ... encourages me to go for maths' (LI, 14 June 2013).

It is imperative that in teaching mathematics, learners understand what is discussed and what is being taught to them. This is even more so in South Africa, since there are 11 official languages ${ }^{3}$ and thus a mathematics class will likely contain learners with diverse languages. However, technology-based lessons aid in eliminating the language barrier since the learner is exposed to visual information rather than verbal information. Many learners such as Bradley experienced the same difficulty with language and trigonometry. This is supported by Bradley's statement:

Especially with like trig I can't comprehend what is being taught if it's spoken to me but were if I see it visually and be able to interact with the technology I understand it better. (LI, 14 June 2013)

\section{Meaningful interaction}

Through observation, it was noted that learners did not experience a learning block. They displayed a high level of confidence and certainty during the completion of the worksheet within the dynamic online environment. This is likely due to the dynamic online environment, which offered a self-explanatory learning process aided by visualisation. The use of technology-based tools in mathematics ensures an answer that is without human error. Thus, technologybased tools are ideal to use when a learner wants to check the validity of their reasoning in a mathematical problem especially when they are not in the classroom with their teacher, peers or tutors.

It is important to note that learners need to initially sketch their graphs by hand. In this way, they demonstrate their skills and understanding of trigonometric graphs. However, it is just as important to expose learners to technology-based tools in mathematics. This notion is validated by Andile's statement:

It's just a new way of thinking about it. It's something different usually we so use by doing it by ourselves by hand and now it kind of broaden our horizons in respect to our way of thinking and feel. (LI, 14 June 2013)

The integration of dynamic online software assists with the visual illustration of the theoretical knowledge the learner currently possess. Tahlia expressed that due to technology

3.The 11 official languages recognised are English, Afrikaans and nine African languages: IsiZulu, IsiXhosa, Setswana, Tshivenda, Xitsonga, Sesotho, IsiNdebele, SiSwati and Sepedi. 
her knowledge about trigonometric graphs 'has heightened because like I said you can see it ...easier' (LI, 14 June 2013).

It is important to note that learners may overcome language and other challenges in mathematics through the use of dynamic online software. Technology-based tools create an external image that is transposed to one's current knowledge. Self-discovery tasks, like the second worksheet in this study, allow learners to investigate, notice and make generalisations before the teacher could explain these to them.

\section{Conclusion}

This study aimed to explore the implications of the use of dynamic online software when teaching trigonometric graphs to a group of Grade 10 mathematics learners. The use of technology in mathematics classrooms is not new. Many technology-based tools are available and may be used in mathematics. Teachers do use slides, movies, cassette players, data projectors and overhead projectors to enrich the teaching and learning process.

In this study, it was apparent that the use of a dynamic online environment allowed learners to develop a well-founded and enhanced mathematical understanding of trigonometric graphs. The dynamic online environment allowed for each trigonometric graph to be visualised and decreased complicated calculations, thus allowing the learner to focus on important and critical ideas. The Geogebra program allowed learners to obtain immediate feedback. This assisted in motivating and enhancing the learners' confidence levels when working with trigonometric graphs in mathematics. Furthermore, the dynamic online environment provided a platform for learner communication after school hours and assisted in overcoming issues associated with language barriers in mathematics. Through actively participating in the lessons, learners achieved and demonstrated a concrete understanding of trigonometric graphs.

Based on the analysis of the data collected from both worksheets, it was evident that learners performed better on the second worksheet. This worksheet was completed within a dynamic online environment. It was evident that learners' skills and knowledge related to answering questions based on trigonometric graphs were enhanced. Based on learner feedback, this improved knowledge and skills were related to the learners being in control of their own learning and seeking immediate feedback and interaction, which was possible within a dynamic online environment.

Moreover, the use of technology-based tools in the classroom is likely to equip learners with computer skills and knowledge. Due to exposure to technology-based tools, learners can become competent in their computer skills thus resulting in a confident tech-savvy generation. Although dynamic online software was used, the teacher was not absent from the teaching and learning process. The teacher acted as the facilitator, which was fundamental and critical to the online learning. The teacher played an instrumental role in fostering and scaffolding learners' mathematical understanding.
Despite acknowledging that the use of technology-based tools improves learning, there are a number of schools and teachers that face a variety of barriers related to issues of cost, lack of expertise, lack of the necessary infrastructure, resistance to change from traditional teaching methodologies, lack of connectivity needed to access Internet services as well as lack of electricity. It is thus important that teachers and learners do not depend entirely on technology-based tools when teaching mathematics. A combination of handson and technology-enhanced activities advance learners' understanding and confidence levels in mathematics. Thus, allowing for a merging of contemporary and traditional teaching and learning strategies in mathematics classrooms enriches the learning process.

\section{Acknowledgements}

We would like to thank the University of KwaZulu-Natal's Teaching and Learning Office for funding part of this study. The opinions expressed here are those of the authors and do not necessarily reflect the position, policies or endorsements of the university.

\section{Competing interests}

No financial or personal relationship(s) have inappropriately influenced the writing of this article.

\section{Authors' contributions}

J.N. (University of KwaZulu-Natal) and R.G. (Kingsway High School) contributed equally to the design and writing of the article and preparation of the manuscript for publication.

\section{References}

Anthony, G., \& Walshaw, M. (2009). Characteristics of effective teaching of mathematics: A view from the West. Journal of Mathematics Education, 2(2) 147-164. Available from http://educationforatoz.org/images/_9734_12_Glenda 147-164. Avarila

Bertram, C. (2010). Research designs and styles of research. In E. Dempster, \& A. James (Eds.), Understanding research - An introduction to reading research (pp. 33-52). Durban: Faculty of Education, University of KwaZulu-Natal.

Bichelmeyer, B.A. (2005). The ADDIE model - A metaphor for the lack of clarity in the field of instructional design theory. Available from http://www.indiana.edu/ idt/ shortpapers/documents/IDTf_Bic.pdf

Clements, D.H., Julie, S., Yelland, N.J., \& Glass, B. (2008). Learning and teaching geometry with computers in the elementary and middle school. In M. Kathleen, \& G.W. Blume (Eds.), Research on technology and the teaching and learning of mathematics: Volume 1, research syntheses (pp. 109-154). New York, NY: Information Age Publishing, Inc.

Danks, S. (2011). The ADDIE model: Designing, evaluating instructional coach effectiveness. ASQ Primary and Secondary Education Brief, 4(5), 1-6.

De Villiers, M. (2013, July). Doing geometry on the internet. Paper presented at the Mathematics: Teaching for understanding AMESA Regional Conference, University of KwaZulu-Natal, Edgewood campus, Durban.

Department of Basic Education. (2011). Curriculum assessment policy statement Mathematics. Pretoria: DBE.

Engelbrecht, J., \& Harding, A. (2005). Teaching undergraduate mathematics on the internet. Educational Studies in Mathematics, 58(2), 235-252. http://dx.doi. org/10.1007/s10649-005-6456-3

Govender, R.G. (2013). Trigonometry graphs. Available from http://govenderrg. wikispaces.com/Trigonometry+Graphs

Hannum, W.H. (2005). Instructional systems development: A thirty year retrospective. Educational Technology, 45(4), 5-21.

Hoehler, J. (2013, August). What is hot and trending in mobile and successfully monetised applications? Paper presented at the Mobile Marketing Association Annual Meeting, Umhlanga, Durban. 
Hoffman, B., Ritchie, D., \& Marshall, J. (2006). ADDIE - An introduction. Available from http://edweb.sdsu.edu/course/EDTEC540/EDTEC540BB/Module3/mod03.htm

Klein, R.J., \& Hamilton, I. (1997). Using technology to introduce radian measure. The Mathematics Teacher, 90(2), 168-172.

Koh, J.H.L., \& Sing, C.C. (2011, December). Modeling pre-service teachers' technological pedagogical content knowledge (TPACK) perceptions: The influence of demographic factors and TPACK constructs. Changing demands, changing directions. Paper presented at the Ascilite Conference, Hobart, Tasmania, Australia.

Leendertz, V., Blignaut, A.S., Nieuwoudt, H.D., Els, C.J., \& Ellis, S.M. (2013) Technological pedagogical content knowledge in South African mathematics classrooms: A secondary analysis of SITES 2006 data. Pythagoras, 34(2), 1-9. http://dx.doi.org/10.4102/pythagoras.v34i2.232

Lin, C.-Y. (2008). Beliefs about using technology in mathematics classroom: Interviews with pre-service elementary teachers. Eurasia Journal of Mathematics, Science and Technology Education, 4(2), 135-142.

Lowe, R. (2001, September). Beyond eye candy - Improving learning with animations. Paper presented at the Face to Face Odyssey: Apple University Consortium Conference, Queensland, Australia.

Mishra, P., \& Koehler, M.J. (2006). Technological pedagogical content knowledge: A framework for teacher knowledge. Teachers College Record, 106(6), 1017-1054. $\mathrm{http}: / / \mathrm{dx}$.doi.org/10.1111/j.1467-9620.2006.00684.x

Morgan, P.J. (2011). Instructional design theory for learning objects: ADDIE. Available from http://pamelajmorgan.org/2011/07/20/instructional-design-theory-for-losaddie/
Morrison, G.R., Ross, S.M., \& Kemp, J.E. (2004). Designing effective instruction. Hobokon, NJ: Wiley \& Sons.

Naidoo, J. (2012). Teacher reflection: The use of visual tools in mathematics. Pythagoras, 33(1), 19-27. http://dx.doi.org/10.4102/pythagoras.v33i1.54

Ndlovu, M., Wessels, D., \& De Villiers, M. (2011). An instrumental approach to modelling the derivate in Sketchpad. Pythagoras, 32(2), 1-15. http://dx.doi. org/10.4102/pythagoras.v32i2.52

Niess, M.L. (2006). Preparing teachers to teach mathematics with technology. Contemporary Issues in Technology and Teacher Education, 6(2), 195-203.

Padayachee, P., Boshoff, H., Olivier, W., \& Harding, A. (2011). A blended learning Grade 12 intervention using DVD technology to enhance the teaching and learning of mathematics. Pythagoras, 32(1), 19-26. http://dx.doi.org/10.4102/pythagoras. v32i1.24

Pierce, R., \& Ball, L. (2009). Perceptions that may affect teachers' intention to use technology in secondary mathematics classes. Educational Studies in Mathematics, 71(3), 299-317. http://dx.doi.org/10.1007/s10649-008-9177-6

Robert, E., \& Slavin, C.L. (2009). Effective programs in middle and high school mathematics: A best-evidence synthesis. Review of Educational Research, 79(2), 839-911. http://dx.doi.org/10.3102/0034654308330968

Vygotsky, L.S. (1978). Mind and society: The development of higher mental processes. Cambridge, MA: Harvard University Press.

Weber, K. (2008). Teaching trigonometric functions: Lessons learnt from research. Mathematics Teacher, 102(2), 144-150. 


\section{Appendix 1}

\section{Pencil and paper worksheet}

\section{Trigonometric graphs}

1. Graph of $y=a \sin b x,-180^{\circ} \leq x \leq 180^{\circ}$

1.1. Sketch the graph of $f(x)=\sin x$ on the graph paper provided.

1.2. If you increase the value of $\boldsymbol{a}$ to 2 , what do you think will happen to the shape of the graph?

1.3. If you decrease the value of $\boldsymbol{a}$ to $1 / 2$, what do you think will happen to the shape of the graph?

1.4. If you increase the value of $\boldsymbol{b}$ to 2 , what do you think will happen to the shape of the graph?

1.5. If you decrease the value of $\boldsymbol{b}$ to $1 / 2$, what do you think will happen to the shape of the graph?

2. Graph of $y=a \cos b x,-180^{\circ} \leq x \leq-180^{\circ}$

2.1. Sketch the graph of $\boldsymbol{g}(\boldsymbol{x})=\cos \boldsymbol{x}$ on the graph paper provided.

2.2. If you increase the value of $\boldsymbol{a}$ to 3 , what do you think will happen to the shape of the graph?

2.3. If you decrease the value of $a$ to $1 / 3$, what do you think will happen to the shape of the graph?

2.4. If you increase the value of $\boldsymbol{b}$ to 3 , what do you think will happen to the shape of the graph?

2.5. If you decrease the value of $\boldsymbol{b}$ to $1 / 3$, what do you think will happen to the shape of the graph?

3. Study the graph below and answer the questions that follow.

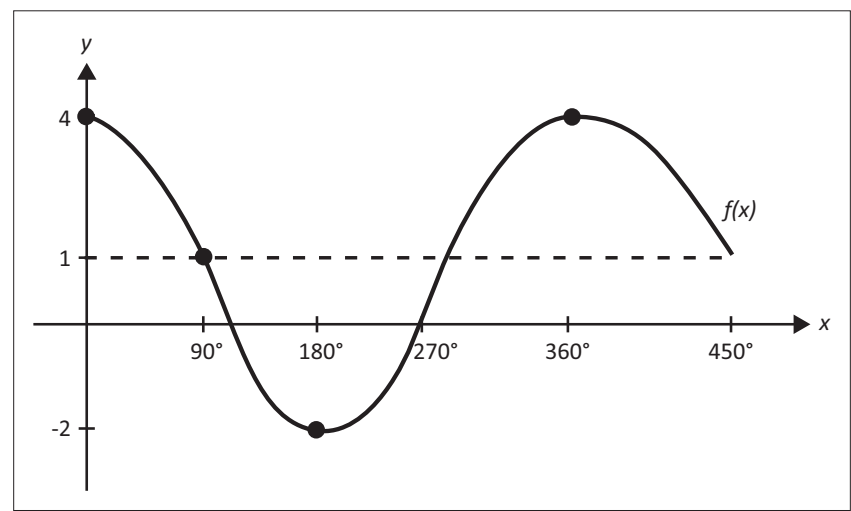

3.1 What is the period of $f(x)$ ?

3.2 Write down the equation of $f(x)$.

3.3 What is the maximum value of $f(x)$ ?

3.4 What is the minimum value of $f(x)$ ?

3.5 Which one of the following statements is correct? (Write down only the correct letter.)
a) $f(x)$ is not symmetrical about any line.
b) $f(x)$ is symmetrical about the $x$-axis.
c) $f(x)$ is symmetrical about the $y$-axis.
d) $f(x)$ is symmetrical about the line $y=x$.

4.

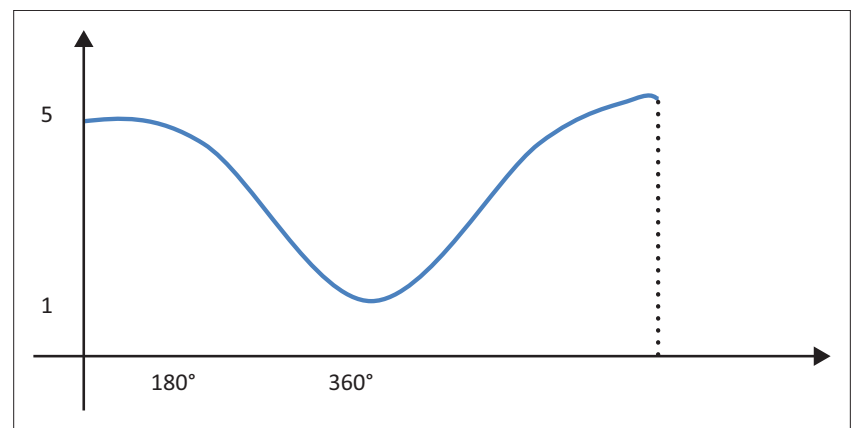

The equation of this graph can be written as $y=c+k \cos \theta$. What are the values of $c$ and $k$ ? 


\section{Appendix 2}

\section{Online activity worksheet}

Step 1: Log onto your computer.

Step 2: Go to the Internet browser and enter: www.govenderrg.wikispaces.com

Step 3: Click on the Trig graphs link along the left-hand side.

\section{Question 1}

Answer the questions (1.1-1.4) below based on the sin and cos graph (click on the $\sin$ and $\cos$ link separately).

1.1

- Set $a=1, b=1, c=0^{\circ}$ and $d=0$

- Move the slider of $a$ so that it increases from 0 to 10.

- Move the slider of $a$ so that it decreases from 0 to -10 .

\begin{tabular}{|l|l|}
\cline { 2 - 2 } \multicolumn{1}{c|}{} & Describe the shape of the graph when: \\
\hline$a>0$ & \\
\hline$a<0$ & \\
\hline
\end{tabular}

1.2

- Set $a=1, b=1, c=0^{\circ}$ and $d=0$

- Move the slider of $d$ so that it increases from 0 to 10.

- Move the slider of $d$ so that it decreases from 0 to -10 .

\begin{tabular}{|l|l|}
\cline { 2 - 2 } \multicolumn{1}{l|}{} & Describe the shape of the graph when: \\
\hline$d>0$ & \\
\hline$d<0$ & \\
\hline
\end{tabular}

\section{Question 2}

Move the sliders $a, b, c, d$ one at a time and match the statement with the unknown.

$y=a \cdot \sin (b \cdot(x \pm c))+\mathrm{d}$

$y=a \cdot \cos (b \cdot(x \pm c))+\mathrm{d}$

\begin{tabular}{|l|l|}
\hline STATEMENT & CHOOSE the appropriate unknown $\boldsymbol{a}, \boldsymbol{b}, \boldsymbol{c}$ or $\boldsymbol{d}$ \\
\hline 2.1 Affects the period (repetitive cycle of graph ) & \\
\hline 2.2 Affects the shifting of the graph (up or down) & \\
\hline 2.3 Affects the amplitude (maximum displacement from $x$ axis) & \\
\hline 2.4 Affects the phase shift (left or right) & \\
\hline
\end{tabular}

\section{Question 3}

The following sound waves show the breathing patterns of two runners

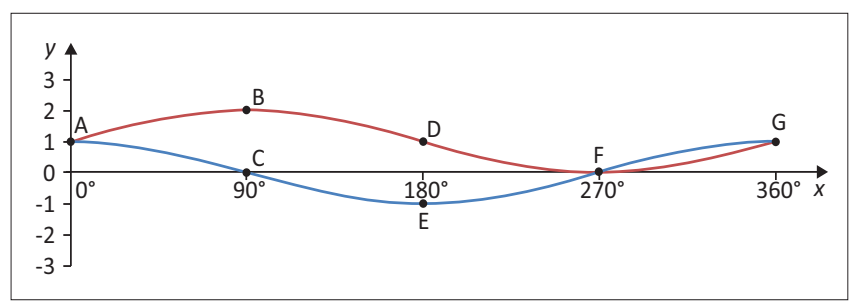

The sketch above shows the graphs $f(x)=\sin x+1$ and $g(x)=\cos x$ where $x \in\left[0^{\circ} ; 360^{\circ}\right]$

Click on the $\sin v \cos$ graph link and set the graphs to $f(x)=\sin x+1$ and $g(x)=\cos x$ 
3.1 Write down the equation of the graph passing through $A, C, E, F$ and $G$.

3.2 What is the amplitude of the graph that passes through points A, B, D, F and G?

3.3 Write down the range of $f(x)=\sin x+1$.

3.4 Write the maximum and minimum values of $f(x)=\sin x+1$.

3.5 Write the maximum and minimum values of $g(x)=\cos x$.

3.6 Write down the coordinates of points B and G.

3.7 Write the equation of the graph that undergoes a horizontal shift from its standard form.

3.8 For which value(s) $x$ is $\cos x>\sin x+1$ ?

\section{Question 4}

The graph below shows one complete normal breathing cycle. The cycle consists of inhaling and exhaling. It takes place every 5 seconds. The velocity of air flow is positive when we inhale and negative when we exhale. It is measured in litres per second.

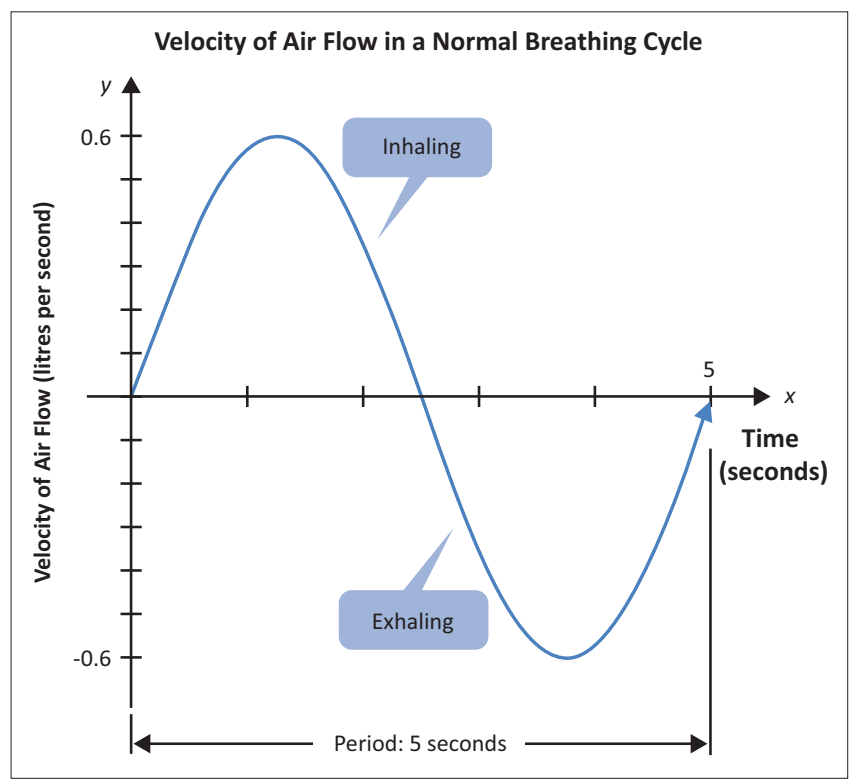

If $y$ represents velocity of air flow after $x$ seconds, find a function of the form $y=A \sin B x$ that models air flow in a normal breathing cycle. HINT: period $=\frac{360^{\circ}}{B}$ and model the above graph using the sin graph online. 


\section{Appendix 3}

\section{Learner semi-structured interview schedule}

1. Do you enjoy doing mathematics?

2. What are your thoughts about the use of technology in the maths classroom (depending on response form question 1)?

3. Is it easier to understand your maths work through the use of technology? Why?

4. What effect does the use of dynamic technology have on your mathematics understanding of concepts being taught?

5. How do you feel about walking into a class that uses technology?

6. With respect to question 5 does this changes your attitude towards doing mathematics?

7. Would the use of technology, such as the tool used in your maths lesson, benefit you later in life?

8. Are you comfortable using technology in maths and why?

9. Would you have understood at the level you did if the lesson had not used technology? Why?

10. Would ever go back to the website to revise the concepts of trigonometric graphs? When (before test, exams, homework, etc.)? Where (at home, school, travel, library, etc.)?

Things to take note whilst doing interview:

- Learner expressions and body movements when responding.

- Emphasis in tone or speech when responding.

- Words and questions learners had problems understanding. 